\title{
Cytokine Expression Profile
}

National Cancer Institute

\section{Source}

National Cancer Institute. Cytokine Expression Profile. NCI Thesaurus. Code C129886.

The identification and quantitation of all of the cytokines expressed in a biological sample. 